\title{
Enthalpy-Entropy Compensation in Polyester Degradation Reactions
}

\begin{abstract}
Adam Al-Mulla
Chemical Engineering Department, Kuwait University, P.O. Box 5969, 13060 Safat, Kuwait

Correspondence should be addressed to Adam Al-Mulla, a.almulla1@ku.edu.kw

Received 22 May 2012; Accepted 28 July 2012

Academic Editor: Adrian Schumpe

Copyright () 2012 Adam Al-Mulla. This is an open access article distributed under the Creative Commons Attribution License, which permits unrestricted use, distribution, and reproduction in any medium, provided the original work is properly cited.

In an earlier work the author had studied the degradation kinetics of polyethylene terephthalate (PET), polytrimethylene terephthalate (PTT), and polybutylene terephthalate (PBT) under nonisothermal conditions in air and $\mathrm{N}_{2}$ at heating rates of $5,10,15$, and $20^{\circ} \mathrm{C} / \mathrm{min}$. In this paper the kinetic degradation parameters of PET, PTT, and PBT were estimated using the CoatsRedfern method for two different weight loss regions ranging from $2-8 \%$ (Zone I) and $8-40 \%$ (Zone II). A comparative analysis of the enthalpy-entropy compensation effect for these polyesters in air and $\mathrm{N}_{2}$ is presented. A linear relationship was found to exist between entropy and enthalpy values. The following criteria were applied to establish an enthalpy-entropy compensation effect and to check the presence of an isokinetic temperature: (a) Exner's plot of $\log k_{3_{T 1}}$ versus $\log k_{3_{T 2}}$, and (b) Krug et al. linear regression of $\Delta H$ versus $\Delta G$. By the use of the latter two methods, varying isokinetic temperatures were obtained. These temperatures were not in the range of the experimental work conducted, indicating that these systems do not display compensation phenomena.
\end{abstract}

\section{Introduction}

Kinetic studies carried out on similar compounds with a correctly chosen mechanism function $f(\alpha)$ ( $\alpha$ is the weight fraction of material decomposed at temperature $T$ and time $t$ ) exhibit a linear relationship between the logarithm of the preexponential factors and activation energies known as the compensation effect [1-5]. Several theories and explanations for such compensation behavior have been put forth [6-8].

In the case of thermal decomposition of solids, the existence of the compensation effect permits certain conclusions concerning the decomposition mechanism and thermal characteristics of the compounds under investigation. The changes of Gibbs energy $(\Delta G)$, enthalpy $(\Delta H)$, and entropy $(\Delta S)$ for the degradation reactions can be obtained by studying the kinetics of the thermal decomposition of solid compounds with nonisothermal heating using the thermogravimetric (TG) curves and a correct algebraic expression of the conversion function, $f(\alpha)$.

The reaction mechanism for polymer degradation is a very complex chain mechanism that includes initiation, propagation, and termination reactions. Normally, two types of reaction models, the first order $f(\alpha)_{1}=(1-\alpha)$ and the second order $f(\alpha)_{2}=(1-\alpha)^{2}$, are used for the thermal degradation studies of polymers.

The author has previously reported [5] the kinetic parameters characterizing the degradation of PET, PTT, and PBT in air and $\mathrm{N}_{2}$ using data from nonisothermal thermogravimetry and the calculation procedure of Coats and Redfern [5].

The aim of this work was to obtain the thermodynamic parameters, $\Delta S, \Delta H$, and $\Delta G$, relating to the degradation of PET, PTT, and PBT and to determine whether the false compensation effect (presence of an isokinetic temperature) observed in the previous work can also be noticed when the thermodynamic parameters (enthalpy-entropy relationship) are used to check the compensation effect. Plots of $\Delta S$ and $\Delta H$ were used to confirm this result.

\section{Theoretical Background}

Mathematical analysis was performed on the TG data using the integral method of Coats and Redfern, [9] which has been used successfully for studies on the kinetics of decomposition of solid substances [10-14]. The activation energy $(E)$ and 
the preexponential factor $(A)$ for the degradation of PET, PTT, and PBT have been previously calculated from the TG curves.

Degradation of polymers can be described with chemical reactions of different rate constants [15]. Because the molecular weight of a chain reduces continuously throughout a process the dependence of chain length becomes weak. Therefore the dependence of rate constant of degradation on molecular weight is normally observed at moderate values of molecular weight [16]. Breakdown of the chain molecules leads to an increase of the number of molecules and a decrease of the length, thus altering the dependence of the system free energy on the molecular length $[16,17]$.

Kinetics of a degradation process can be described by the theory of activated complexes $[18,19]$. On assuming that the system equilibrium can be achieved faster at given composition of solution, than the ongoing degradation process the constant rate of reaction can be defined by free energies of formation of initial chain and activated complex by [2022]:

$$
k=\frac{x e k_{B} T}{h} \exp \left(\frac{\Delta S}{R}\right) \exp \left(-\frac{E}{R T}\right),
$$

where $k$ is the degradation rate constant, $x$ is a transmission coefficient (unity for monomolecular reactions), $k_{B}$ is the Boltzmann constant, $h$ is the corresponding Planck's constant, $e=2.7183$ is the Neper number, and $\Delta S$ is the change of entropy for the active complex formation [23]. Equation (1) is based on the basic Arrhenius equation:

$$
k=A e\left(\frac{-E}{R T}\right),
$$

where $A$ is the preexponential factor, $E$ is the activation energy, $T$ is the temperature, and $R$ is the universal gas constant.

Taking into account the preexponential constant $A$, the following expression is obtained:

$$
A=\frac{x e k_{B} T}{h} \exp \left(\frac{\Delta S}{R}\right),
$$

and $\Delta S$ can be calculated as follows:

$$
\Delta S=R\left(\ln A-\frac{\ln x e k_{B} T}{h}\right),
$$

where $A$ is the preexponential factor in the Arrhenius equation. Because

$$
E=\Delta H+R T
$$

The change of the enthalpy $\Delta H$ and Gibbs free energy $\Delta G$ can be calculated using the following equation:

$$
\Delta G=\Delta H-T \Delta S .
$$

$\Delta S, \Delta H$, and $\Delta G$ were calculated at $T=T_{p}$ ( $T_{p}$ is the differential peak temperature. This temperature characterizes the highest rate of the process).

\section{Experimental}

3.1. Materials. PET, PTT, and PBT with number average molecular weight $(\mathrm{Mn})=20,000,28,000$, and 26,000 used here was a product of Century Enka. Ltd. (India).

3.2. Polymer Degradation. To determine the kinetic degradation parameters, all the polymers were subjected to TGA. The decomposition temperatures for PET, PTT, and PBT were measured using an SDT 2960 simultaneous DSCTGA instrument supplied by TA Instruments Ltd. The TGA machine was calibrated using ASTM method, E 1582-93, "standard practice for calibration of temperature scale for thermogravimetry" (ASTM, 1993). The heating rates chosen were $5,10,15$, and $20^{\circ} \mathrm{C} / \mathrm{min}$, and the temperature range scanned was 30 to $700^{\circ} \mathrm{C}$. The weight loss of the polymers was determined by loading 7-8 $\mathrm{mg}$ into a platinum crucible and heating it at one of the rates chosen under a steady flow of air and nitrogen $(20 \mathrm{~mL} / \mathrm{min})$. The output signals from the TA 2960 analyzer were fed to a computer interface, where the data was stored.

\section{Results and Discussion}

PET, PTT, and PBT were analyzed using a differential scanning calorimeter (DSC) to determine its melting point. The melting points were found to be 254,240 , and $227^{\circ} \mathrm{C}$, respectively. Differential thermal analysis (DTA) of the thermograms for PET, PTT, and PBT revealed that the maximum weight loss temperature for degradation occurred at around $40 \%$ weight loss [5]. Initial weight loss till around 2 weight percent was not considered since it could be due to volatilization of low molecular weight compounds present in the polymers.

The thermograms for all the three polymers had two linear regions (2-8\% (Zone 1) and 8-40\% (Zone 2)) having correlation coefficient $(r)$ above 0.99 was found for all the three polymers. Figure 1 indicates the linear region obtained for zone $1(2-8 \%)$ which corresponds to the horizontal portion of the degradation curve, while Figure 2 indicates the linear region for zone 2 which corresponds to the vertical portion of the thermogram covering the range $8-40 \%$. The maximum rate of weight loss temperature $\left(T_{p}\right)$ (peak of differential thermal analysis (DTG) curve) was obtained from the thermogravimetric data using the manufacturer thermal analysis software.

The Coats Redfern (CR) integral method was used in the previous work [5] to estimate the degradation kinetic parameters $\ln A$ and $E$. The CR equation is given as follows:

$$
\ln \left(\frac{g(\alpha)}{T^{2}}\right)=\left(\frac{A R}{E \beta}\right)-\frac{E}{R T},
$$

where $\beta$ is the heating rate and the other parameters are the same as those found in the equations above.

First order $\left(f(\alpha)_{1}=(1-\alpha)\right)$ and a second order $\left(f(\alpha)_{2}=\right.$ $\left.(1-\alpha)^{2}\right)$ models, the integral forms of which are $\mathrm{g}(\alpha)_{1}=$ $[-\ln (1-\alpha)]$ and $g(\alpha)_{2}=\left[(1-\alpha)^{-1}-1\right]$, [23] were fitted to the Coats-Redfern (7) to obtain the activation energy $(E)$ 


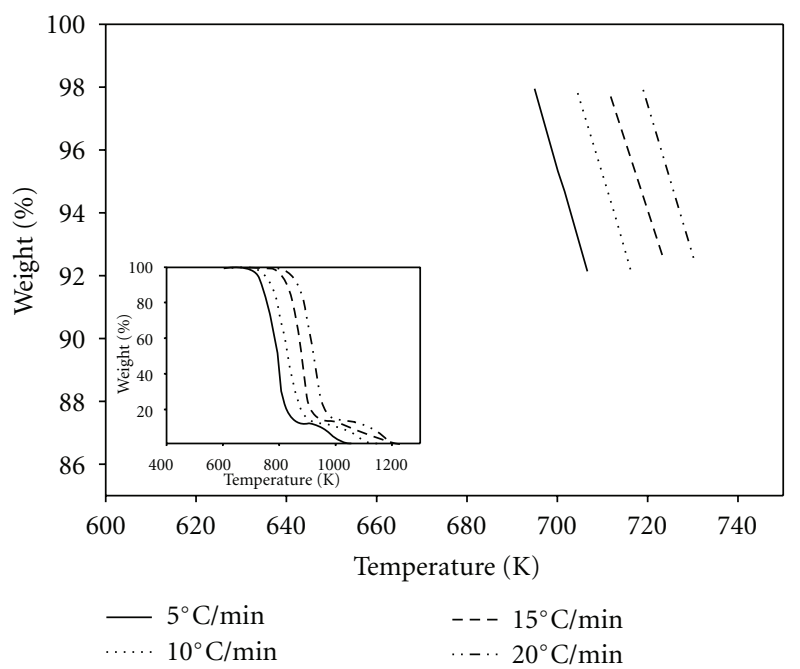

(a) PET

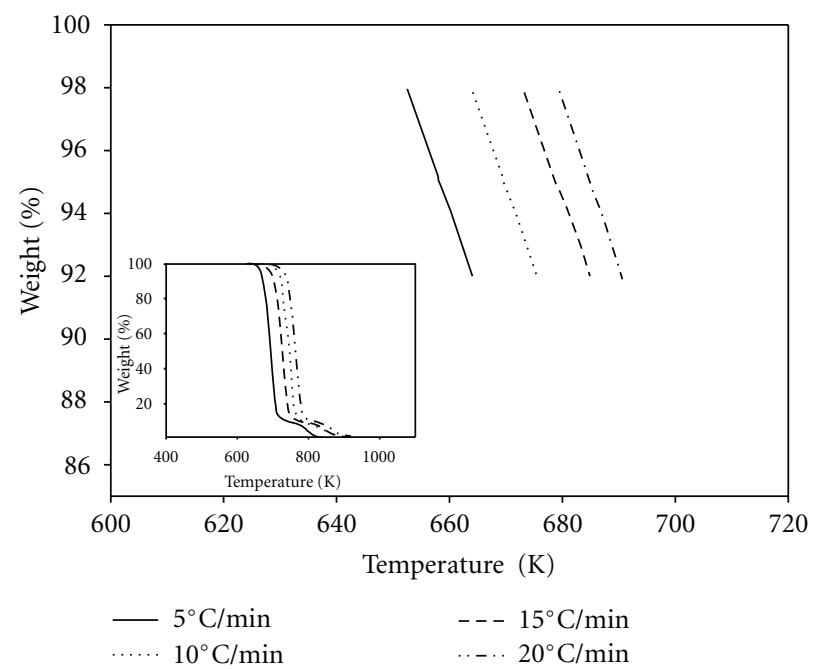

(b) PTT

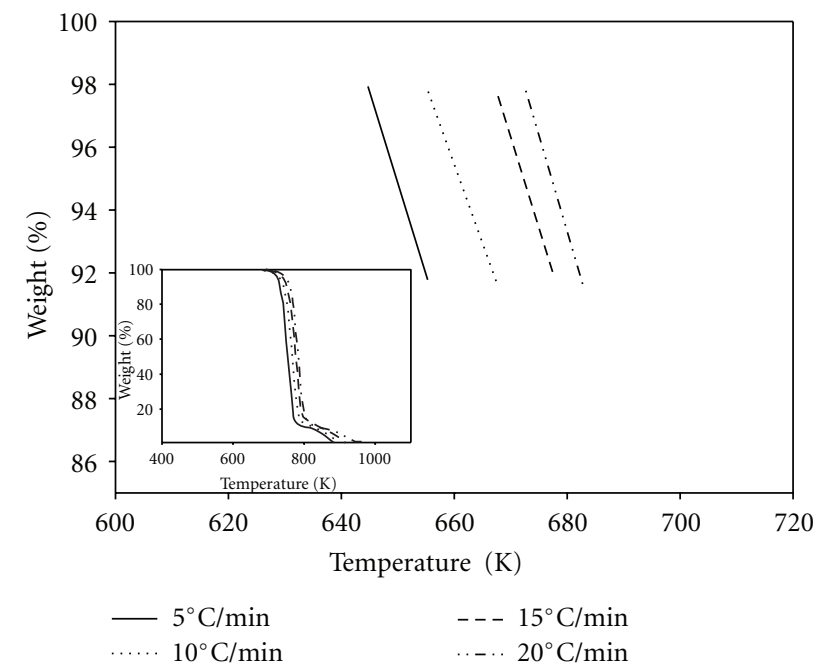

(c) PBT

Figure 1: Plot of weight loss (2-8\% conversion range) as a function of temperature for polyester degradation in air atmosphere (zone 1).

and the preexponential factor for degradation of these polyesters. The $E$ and $A$ for the two different $g(\alpha)$ functions were calculated at constant heating rates by fitting $\ln g(\alpha) / T^{2}$ versus $1 / T$ plots. It was observed that when $g(\alpha)_{1}$ was used for the Arrhenius parameter estimation in the CR equation, correlation coefficient values greater than 0.99 was obtained (Figure 3). When $g(\alpha)_{2}$ was used in the CR equation, the plots obtained had a correlation coefficient less than 0.97. Figure 4 is a plot indicating the poor fit.

Figures 5 and 6 indicate that linear plots obtained between $\ln A$ and $E$ using Arrhenius equation. It has correlation coefficients greater than 0.99 for all the polyesters degraded in air and $\mathrm{N}_{2}$. In some systems, $[24,25]$ it has been observed that the activation energy varies under different measuring conditions. It is also found that the variation in activation energy is accompanied by a change in $A$ that is; a large activation energy is accompanied by a large preexponential factor and vice versa, a phenomena often referred to as compensation effect.
The frequency factor $(A)$ given in (3) contains an entropy term $(\exp \Delta S / R)$. The values of $A$ will reflect in a specific way on the change of entropy for the formation of degradation products from the solid polymer. The enthalpy-entropy and free energy values computed using (3), (5), and (6) are reported in Table 1. It is noted that higher $E$ has low entropy values. The $\Delta S$ values are also found to be negative. As anticipated, the graphical representation of the dependence between the values of $\Delta S$ and $E$ for the polyesters studied shows a linear relationship for all the systems (Figures 7 and 8). Another obvious relationship found from these plots is the existence of a linear relationship between $\Delta S$ and $E$ which implies a direct proportionality between these two quantities. The $E$ values thus have an effect on the values of the change in entropy. As the value of $E$ increases, the value of $\Delta S$ was also found to increase for all the polyesters. The relationships observed can be interpreted, first, as a proof that the activated complex (before forming gaseous products) had a less organized structure and the rearrangements taking place were 


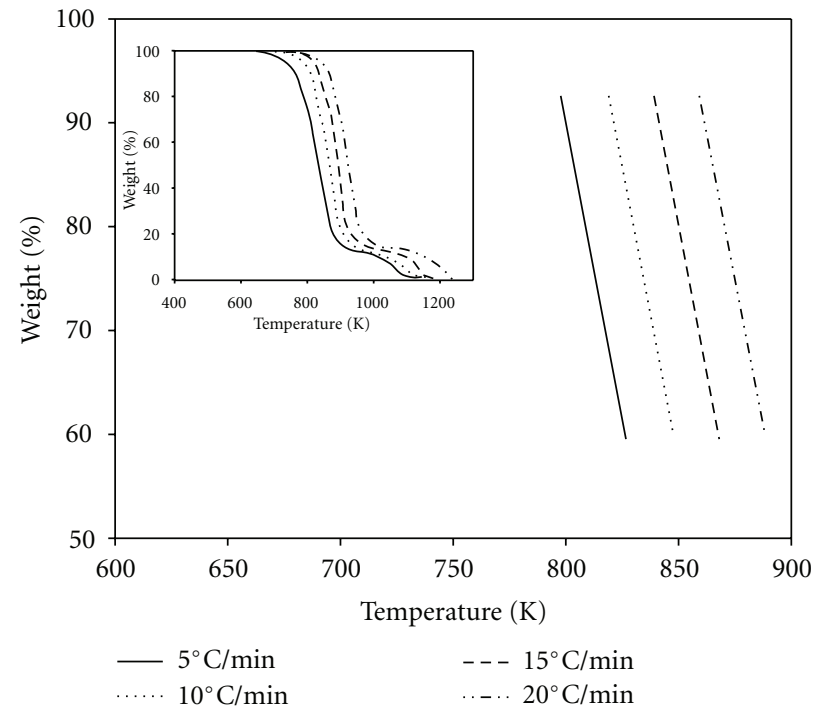

(a) PET

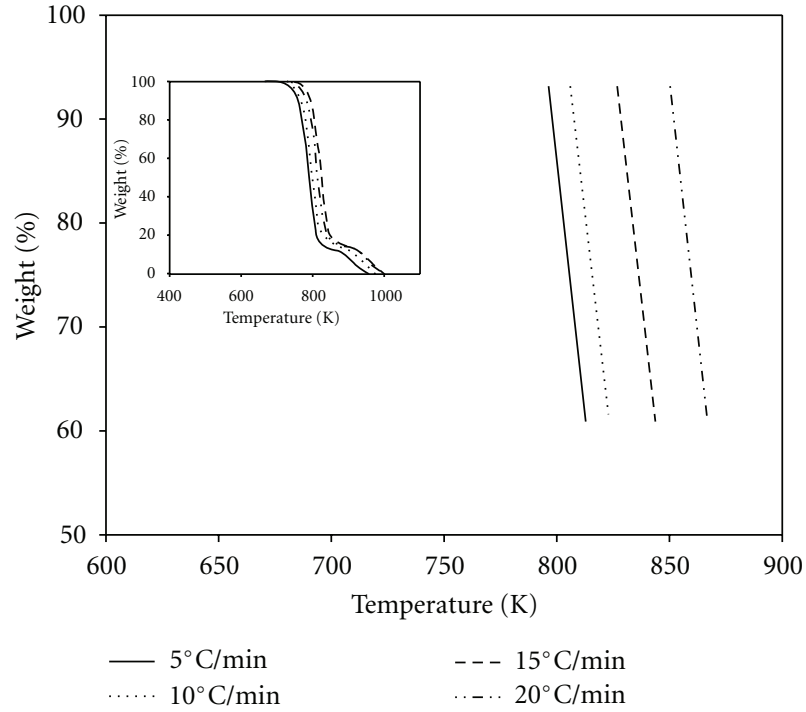

(b) PTT

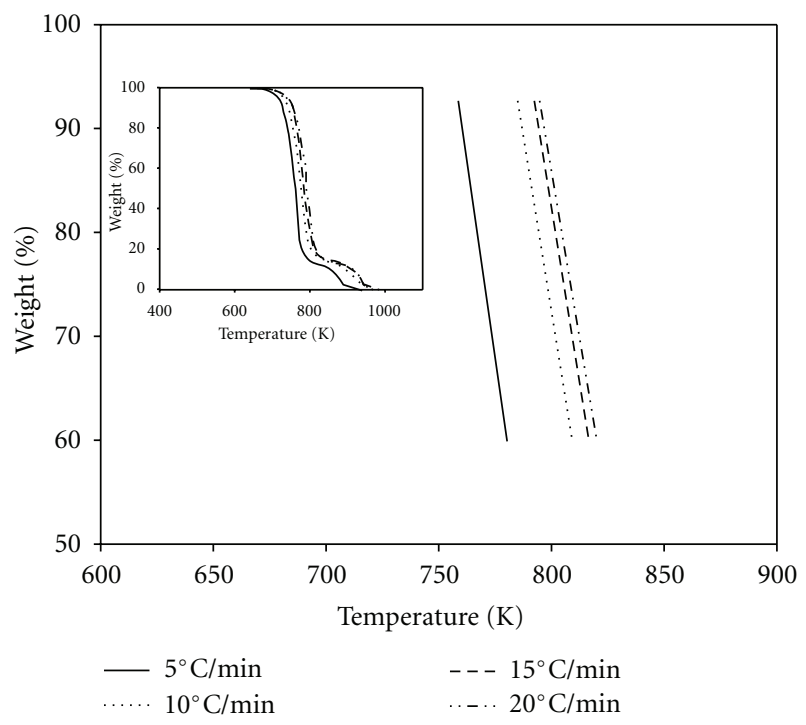

(c) PBT

FIgURE 2: Plot of weight loss (8-40\% conversion range) as a function of temperature for polyester degradation in $\mathrm{N}_{2}$ atmosphere (zone 2).

accompanied by an increase in the entropy of the system. The degrees of freedom of the unstable activated complex formed before degradation into gaseous products were more than the degrees of freedom of the parent polyester. The slopes and the intercepts of the lines observed in Figures 7 and 8 were found to be not identical, possibly indicating that there could be different dissimilar chemical processes. Figures 7 and 8 show that the value of $\Delta S$ for PET was higher than that for PTT and PBT, possibly implying that the corresponding activated complexes for PET degradation have a lower degree of arrangement (higher entropy) than the initial state. According to the theory of the activated complex, [26] thermal degradation of PBT and PTT may be interpreted as a fast reaction, while thermal degradation of PET is a slow reaction. The correlation coefficient $(r)$ values of the latter plots werefound to be greater than 0.99. In deducing the compensation effect from temperature dependent data, the temperature dependence of a suitable kinetic parameter, $k$, is analyzed by making Arrhenius plots of $\ln k$ versus $1 / T$. The slope and intercept of the resulting plots are reprocessed in the light of the theory of formation of an active complex [20] to yield estimates of enthalpy and entropy. The values of enthalpy and entropy given in Table 1 tells us about the changes in the internal structure or organization during the degradation process. The majority of the researchers have concluded that thermodynamic compensation in any chemical reaction occurs because of the linear relationship of the enthalpy-entropy plot, which is supported by the high correlation coefficient [24]. Plotting enthalpy against entropy yields a "compensation plot," typically a straight line when 
TABLE 1: Kinetic characteristics of different polyesters.

\begin{tabular}{|c|c|c|c|c|c|c|c|c|c|c|c|c|c|c|c|c|c|c|}
\hline & \multicolumn{6}{|c|}{ PBT-N 2} & \multicolumn{6}{|c|}{ PTT-N 2} & \multicolumn{6}{|c|}{ PET-N 2} \\
\hline & $\beta$ & $T_{p}$ & $E$ & $\Delta S$ & $\Delta G$ & $\Delta H$ & $\beta$ & $T_{p}$ & E & $\Delta S$ & $\Delta G$ & $\Delta H$ & $\beta$ & $T_{p}$ & E & $\Delta S$ & $\Delta G$ & $\Delta H$ \\
\hline \multirow{4}{*}{ Zone 1} & 5 & 648 & 270 & -0.015 & 275 & 265 & 5 & 673 & 439 & -0.022 & 448 & 433 & 5 & 695 & 483 & -0.169 & 594 & 477 \\
\hline & 10 & 669 & 278 & -0.011 & 280 & 273 & 10 & 693 & 450 & -0.022 & 458 & 444 & 10 & 710 & 494 & -0.148 & 593 & 488 \\
\hline & 15 & 674 & 295 & -0.005 & 292 & 289 & 15 & 718 & 429 & -0.025 & 441 & 423 & 15 & 717 & 480 & -0.174 & 599 & 474 \\
\hline & 20 & 682 & 281 & -0.010 & 283 & 276 & 20 & 726 & 429 & -0.025 & 441 & 423 & 20 & 725 & 475 & -0.182 & 601 & 469 \\
\hline \multirow{6}{*}{ Zone 2} & 5 & 771 & 253 & -0.016 & 258 & 246 & 5 & 799 & 310 & -0.027 & 326 & 304 & 5 & 901 & 459 & -0.031 & 480 & 452 \\
\hline & 10 & 793 & 273 & -0.012 & 276 & 266 & 10 & 822 & 370 & -0.022 & 381 & 363 & 10 & 972 & 470 & -0.029 & 490 & 462 \\
\hline & 15 & 800 & 295 & -0.008 & 294 & 288 & 15 & 834 & 379 & -0.021 & 389 & 372 & 15 & 949 & 443 & -0.036 & 470 & 435 \\
\hline & 20 & 807 & 266 & -0.013 & 270 & 259 & 20 & 848 & 290 & -0.031 & 309 & 283 & 20 & 973 & 430 & -0.042 & 463 & 422 \\
\hline & \multicolumn{6}{|c|}{ PBT-AIR } & \multicolumn{6}{|c|}{ PTT-AIR } & \multicolumn{6}{|c|}{ PET-AIR } \\
\hline & $\beta$ & $T_{p}$ & E & $\Delta S$ & $\Delta G$ & $\Delta H$ & $\beta$ & $T_{p}$ & E & $\Delta S$ & $\Delta G$ & $\Delta H$ & $\beta$ & $T_{p}$ & E & $\Delta S$ & $\Delta G$ & $\Delta H$ \\
\hline \multirow{4}{*}{ Zone 1} & 5 & 652 & 304 & -0.031 & 318 & 298 & 5 & 657 & 328 & -0.045 & 352 & 323 & 5 & 701 & 397 & -0.168 & 509 & 391 \\
\hline & 10 & 663 & 390 & -0.015 & 395 & 385 & 10 & 671 & 397 & -0.033 & 413 & 391 & 10 & 706 & 463 & -0.151 & 564 & 457 \\
\hline & 15 & 670 & 382 & -0.017 & 388 & 376 & 15 & 679 & 411 & -0.030 & 426 & 405 & 15 & 719 & 446 & -0.157 & 552 & 440 \\
\hline & 20 & 676 & 407 & -0.012 & 410 & 402 & 20 & 686 & 389 & -0.037 & 408 & 383 & 20 & 725 & 402 & -0.167 & 517 & 396 \\
\hline \multirow{4}{*}{ Zone 2} & 5 & 767 & 184 & -0.036 & 205 & 178 & 5 & 763 & 274 & -0.040 & 298 & 268 & 5 & 901 & 309 & -0.029 & 328 & 302 \\
\hline & 10 & 790 & 207 & -0.021 & 216 & 200 & 10 & 787 & 300 & -0.036 & 321 & 293 & 10 & 905 & 391 & -0.019 & 401 & 383 \\
\hline & 15 & 805 & 196 & -0.027 & 212 & 190 & 15 & 803 & 296 & -0.036 & 318 & 289 & 15 & 928 & 432 & -0.013 & 436 & 424 \\
\hline & 20 & 808 & 179 & -0.042 & 205 & 172 & 20 & 823 & 280 & -0.039 & 305 & 273 & 20 & 950 & 382 & -0.021 & 393 & 374 \\
\hline
\end{tabular}

$\beta$ : heating rate $\left({ }^{\circ} \mathrm{C} / \mathrm{min}\right), T_{p}$ : peak degradation temperature $\left({ }^{\circ} \mathrm{C}\right), E$ : activation energy $(\mathrm{kJ} / \mathrm{mol}), \Delta S$ : change in entropy $(\mathrm{kJ} / \mathrm{mol}), \Delta G$ : change in free energy $(\mathrm{kJ} / \mathrm{mol}), \Delta H$ : change in enthalpy $(\mathrm{kJ} / \mathrm{mol})$.

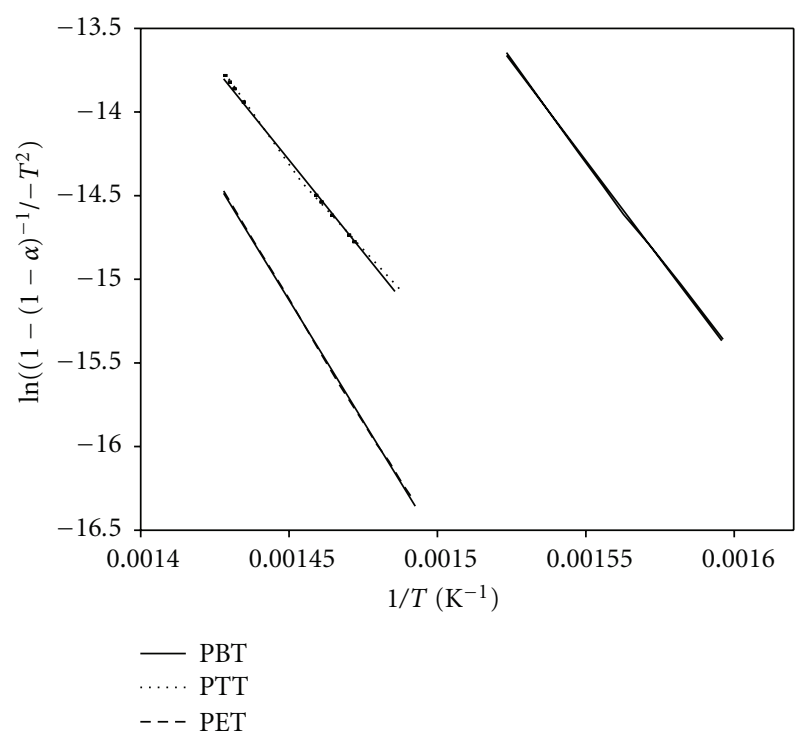

Figure 3: Plot of $\ln \left[1-(1-\alpha)^{-1}\right] /-T^{2}$ versus $1 / T$ for different polyesters degraded in air atmosphere (zone 1).

the compensation effect is noted in the system under investigation. The name "compensation effect" refers to the idea that variations in enthalpy that accompany variations in temperature where molecular level splitting of the polymer occurs during degradation are "compensated for" by variations in change in enthalpy. Figures 9 and 10 show variation of enthalpy as a function of entropy. As seen in Table 1 values of enthalpy and entropy is affected by varying heating rates.

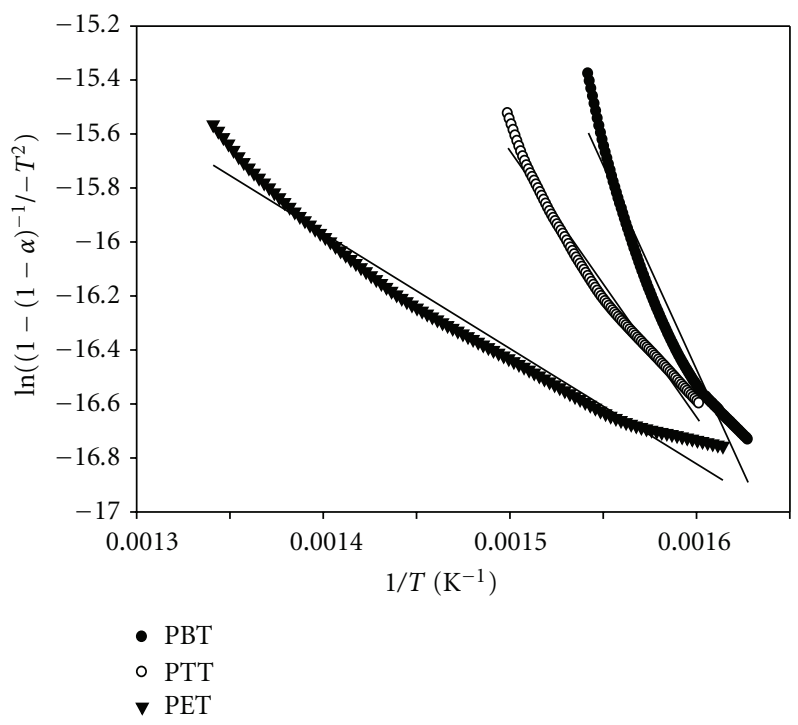

Figure 4: Plot of $\ln \left[1-(1-\alpha)^{-1}\right] /-T^{2}$ versus $1 / T$ for different polyesters degraded in $\mathrm{N}_{2}$ atmosphere (zone 1).

Free energy values are also found to be varying. This type of behavior might be an indication that enthalpy-entropy compensation effect does not operate in such systems [27]. According to Exner [28], a criterion for the existence of a compensation effect is the linear relationship of kinetic constants at two temperatures:

$$
\log k_{3_{T 1}}=b \log k_{3_{T 2}}+\text { const, }
$$




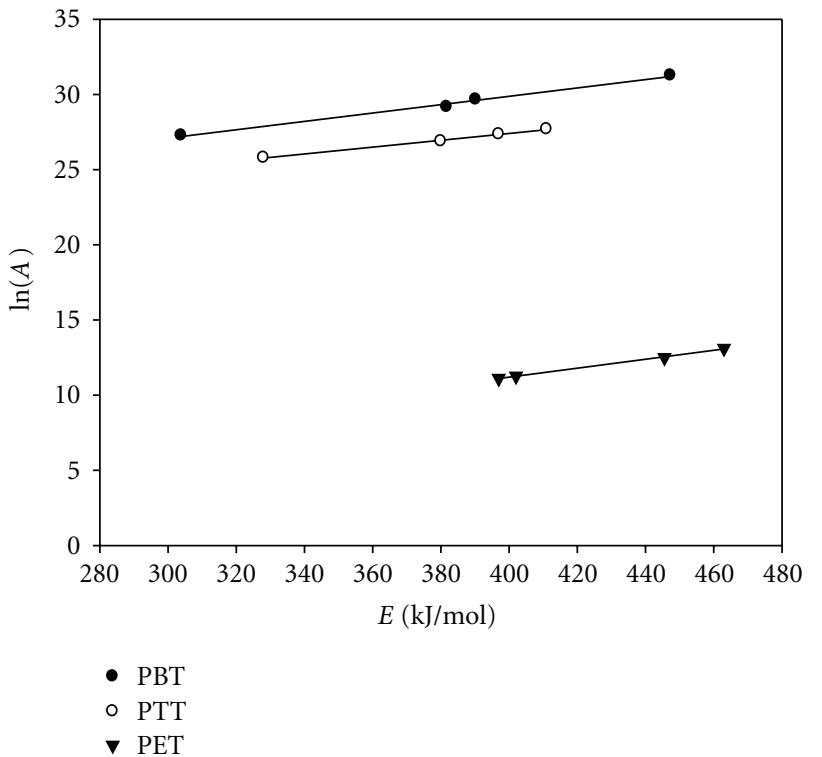

Figure 5: Plot indicating a linear relationship between $\ln A$ versus $E$ for different polyesters degraded in air atmosphere (zone 1).

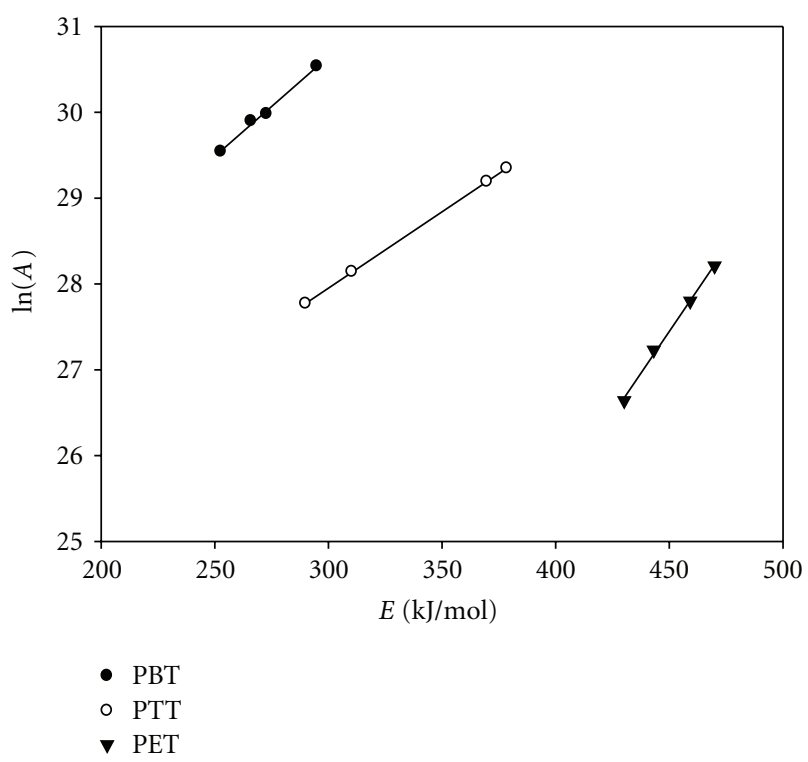

Figure 6: Plot indicating a linear relationship between $\ln A$ versus $E$ for different polyesters degraded in $\mathrm{N}_{2}$ atmosphere (zone 2).

where $k_{3_{T 1}}$ and $\log k_{3_{T 2}}$ are kinetic constants at two different temperatures $T_{1}$ and $T_{2}$.

The slope $b$ is related to the isokinetic temperature $(\Phi)$ by the following equation:

$$
\Phi=T_{1} T_{2} \frac{b-1}{b T_{1}-T_{2}} \quad\left(T_{1}>T_{2}\right) .
$$

The values of $\log k_{3_{T 1}}$ and $\log k_{3_{T 2}}$ were determined from the experiments. A plot of $\log k_{3660 \mathrm{k}}$ versus $\log k_{3680 \mathrm{k}}$ for PBT in $\mathrm{N}_{2}$ atmosphere (zone 1) is indicated in Figure 11. The dependence of both the temperatures for this plot was found

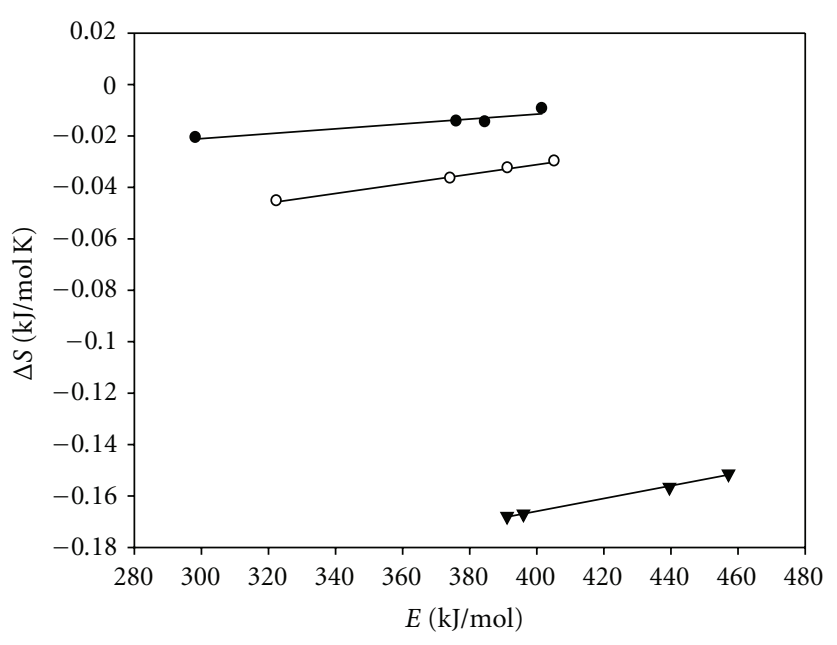

- $\mathrm{PBT}$

- PTT

$\checkmark$ PET

FIgURE 7: Plot indicating a linear relationship of $\Delta S$ versus $E$ for different polyesters degraded in air atmosphere (zone 1).

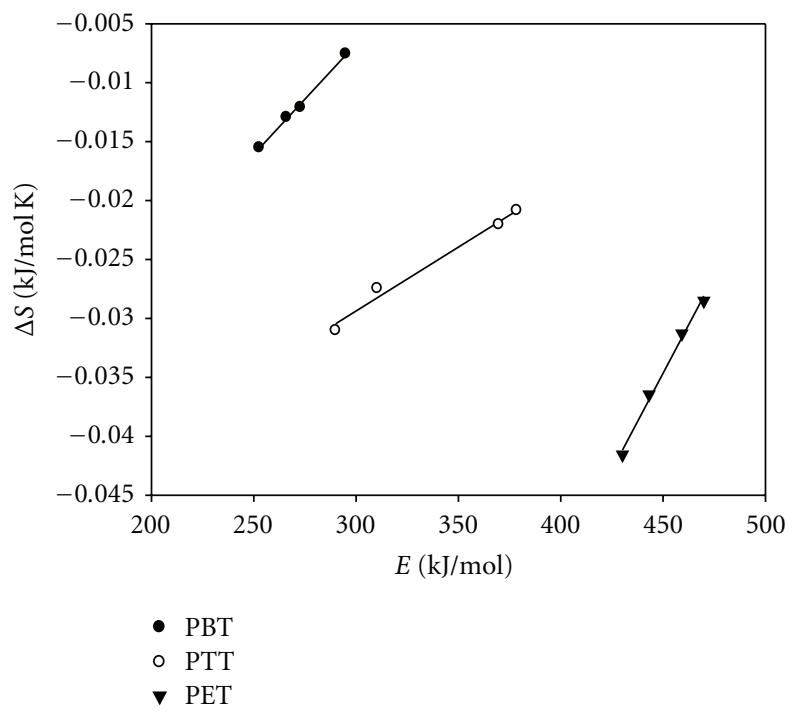

FIGURE 8: Plot indicating a linear relationship of $\Delta S$ versus $E$ for different polyesters degraded in $\mathrm{N}_{2}$ atmosphere (zone 2).

to be linear with an $r$ value of 0.99 and slope $(b)$ equal to $0.852 \pm 0.156$. Estimations were also conducted for $\log k_{3620 \mathrm{k}}$ versus $\log k_{3_{630 \mathrm{k}}}$ and $b$ value was found to be $0.842 \pm 0.2$ with an $r$ of 0.99. Even though a good $r$ was obtained for both the plots, the isokinetic temperature for both the temperature ranges $\left(660-680^{\circ} \mathrm{K}\right.$ and $\left.620-630^{\circ} \mathrm{K}\right)$ were obtained as $990^{\circ} \mathrm{K}$ $\pm 150^{\circ} \mathrm{K}$ and $1010^{\circ} \mathrm{K} \pm 210^{\circ} \mathrm{K}$ which indicated that an isokinetic temperature obtained using (9) does not lie in the experimental range studied. The author in an earlier work [5] tried to employ the criterion used by Peterson and Kevan [29] to check the presence of compensation effect. In this work $\ln k$ verses $1 / T$ was plotted to check the presence of compensation effect operating in these system. An isokinetic 


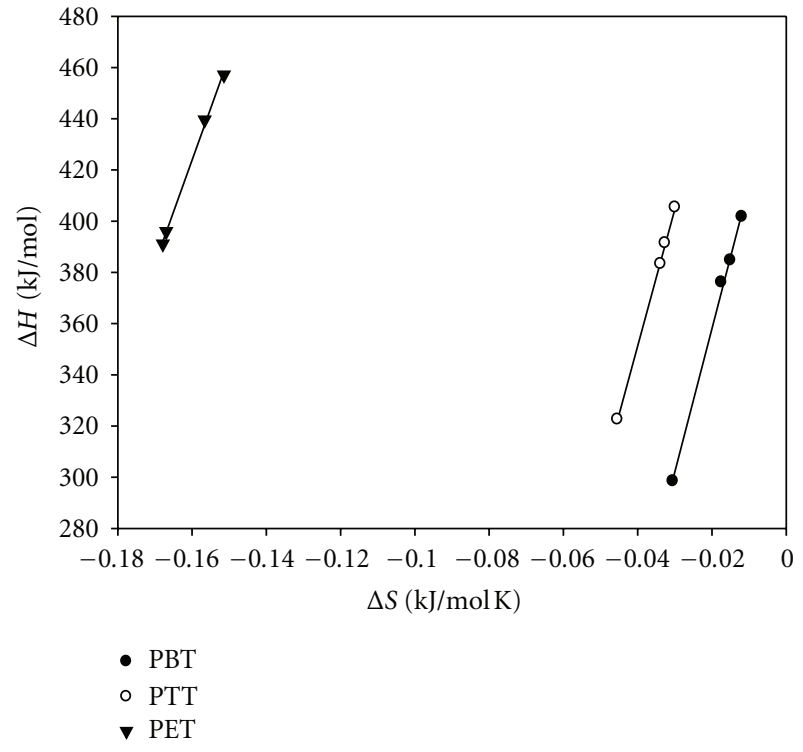

Figure 9: Plot of change in enthalpy as a function of change in entropy for the degradation of different polyesters in air atmosphere (zone 1).

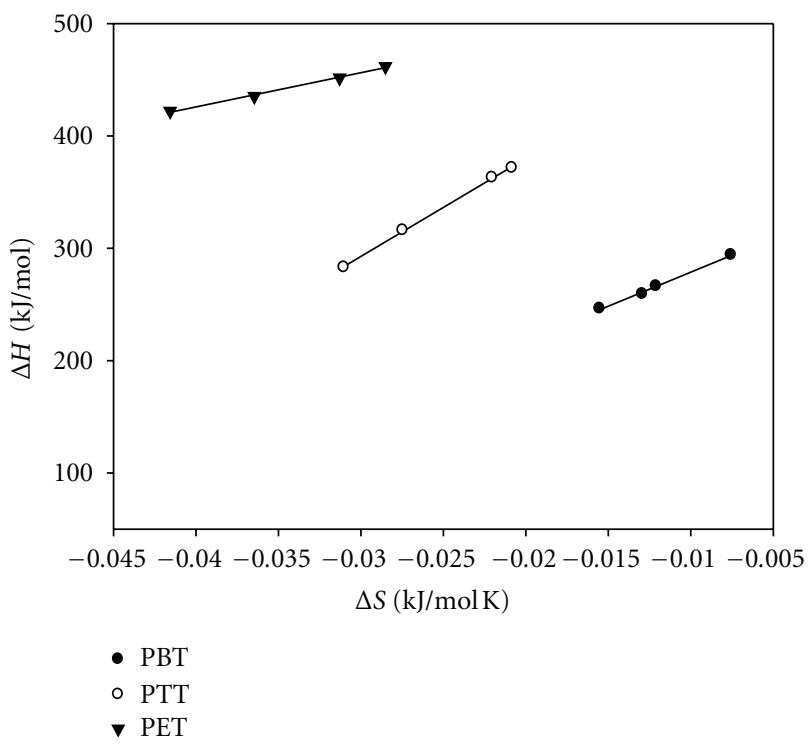

FIGURE 10: Plot of change in enthalpy as a function of change in entropy for the degradation of different polyesters in $\mathrm{N}_{2}$ atmosphere (zone 2).

temperature (temperature at which all the lines concur to a single point) was not obtained in these plots proving the absence of compensation effect.

Another plot (Figure 12) was made to check the variation of $\Delta H$ as a function of $\Delta G$ [30]. A linear relationship with a slope $\gamma$ was obtained. The slope $\gamma$ is related to the isokinetic temperature $(\Phi)$ by the following equation:

$$
\Phi=\frac{T_{h m}}{1-(1 / \gamma)}
$$

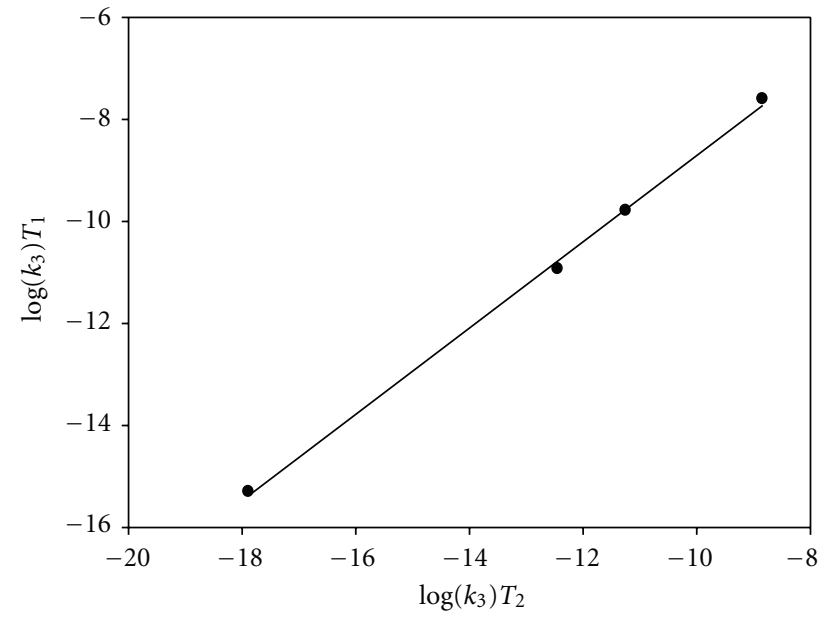

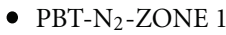

FIGURE 11: Plot of $\log k_{3660}$ versus $\log k_{3_{680}}$ for PBT in $\mathrm{N}_{2}$ atmosphere (zone 1).

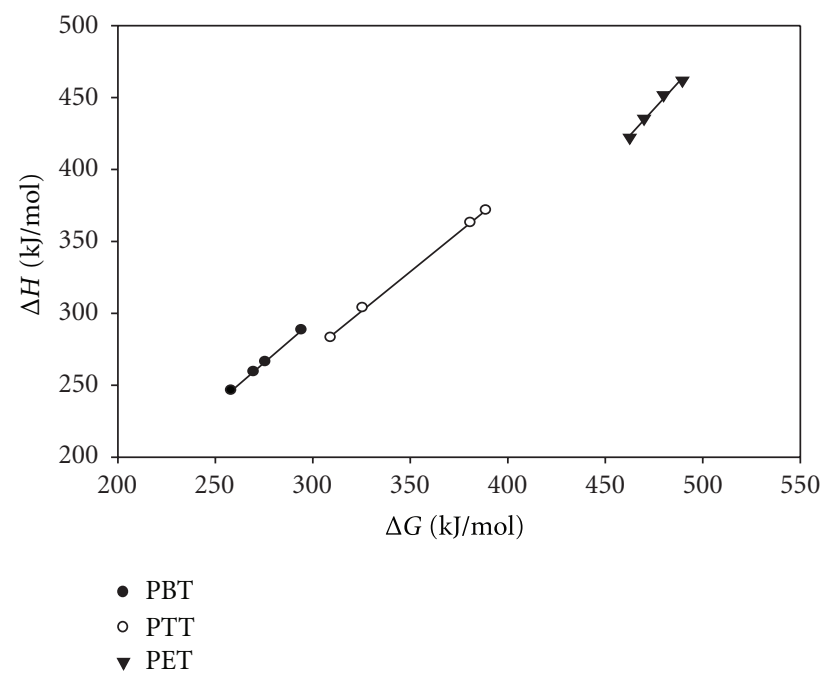

Figure 12: Plot of enthalpy change as a function of free energy change for different polyesters in $\mathrm{N}_{2}$ atmosphere (zone 2).

where $T_{h m}$ is the harmonic mean of experimental temperatures. The value of $\gamma$ was obtained from the plot of enthalpy and free energy and the corresponding value of $\Phi$ were obtained from (10). In this case $\Phi$ was found to be $1089^{\circ} \mathrm{K} \pm$ $120^{\circ} \mathrm{K}$, which is not within the limits of the temperature range conducted in this study, thus proving that compensation effect does not exist in the degradation of PET, PBT, and PTT.

\section{Conclusions}

The Coats-Redfern equation was used to calculate the values of activation energy and the preexponential factor $(A)$ for the nonisothermal degradation of PET, PTT, and PBT in $\mathrm{N}_{2}$ and air atmospheres. A linear dependence was found by 
plotting $\ln A$ and activation energy. A linear relationship was also found to exist between changes in entropy and enthalpy of activation for the degradation of these polyesters. These dependences are related to the assumption that the kinetic degradation mechanisms of these polyesters could be identical. The negative values of entropy show that the degradation activated complex is a more organized structure than the initial polymer structure. The slopes and the intercepts of the lines for the plot of entropy versus activation energy were found to be not identical, possibly indicating that there could be different dissimilar chemical processes occurring on degradation.

The positive values of free energy and enthalpy indicate that the polyester degradation process is a nonspontaneous reaction.

\section{Acknowledgment}

The principal author is grateful to the Research Department of Kuwait University for providing funds from Project EC01/08 for performing this research work.

\section{References}

[1] R. López-Fonseca, I. Landa, M. A. Gutiérrez-Ortiz, and J. R. González-Velasco, "Non-isothermal analysis of the kinetics of the combustion of carbonaceous materials," Journal of Thermal Analysis and Calorimetry, vol. 80, no. 1, pp. 65-69, 2005.

[2] J. Norwisz and T. Musielak, "Compensation law again," Journal of Thermal Analysis and Calorimetry, vol. 88, no. 3, pp. 751-755, 2007.

[3] D. Dos Santos Dias, M. S. Crespi, and C. A. Ribeiro, "Non-isothermal decomposition kinetics of the interaction of poly(ethylene terephthalate) with alkyd varnish," Journal of Thermal Analysis and Calorimetry, vol. 94, no. 2, pp. 539-543, 2008.

[4] B. Janković, L. Kolar-Anić, I. Smičiklas, S. Dimović, and D. Arandelović, "The non-isothermal thermogravimetric tests of animal bones combustion. Part. I. Kinetic analysis," Thermochimica Acta, vol. 495, no. 1-2, pp. 129-138, 2009.

[5] A. Al-Mulla, "Kinetic investigation of compensation effect in degradation of polyesters-1. Under revision in Euro," Polymer Journal. In press.

[6] M. E. Brown, D. Dollimore, and A. K. Galwey, "Reactions in the solid state," in Comprehensive Chemical Kinetics, vol. 22, p. $1,1980$.

[7] P. D. Garn, "The kinetic compensation effect," in Proceedings of the 4th International Conference on Thermal Analysis (ICTA'74), I. Buzas, Ed., vol. 1 of Thermal Analysis, pp. 25-31, 1974.

[8] A. V. Nikolaev, V. A. Logvinenko, V. M. Gorbatchov, and L. I. Myachina, "Thermal Analysis," in in Proceedings of the 4th International Conference on Thermal Analysis (ICTA'74), vol. 1, p. 205, 1974.

[9] A. W. Coats and J. P. Redfern, "Kinetic parameters from thermogravimetric data II," Journal of Polymer Science Part B, pp. 3917-3920, 1965.

[10] V. Indira and G. Parameswaran, "Thermal decomposition kinetics of Schiff base complexes of copper(II) and palladium(II)," Journal of Thermal Analysis, vol. 32, no. 4, pp. 11511162, 1987.
[11] P. V. Khadikar, "Structure and thermal characterization of tristhallium(III) glycollate," Journal of Thermal Analysis, vol. 32, no. 3, pp. 737-748, 1987.

[12] N. S. Petro and B. S. Girgis, "Dehydration kinetics of hydrated iron oxide from dynamic thermogravimetry," Journal of Thermal Analysis, vol. 34, no. 1, pp. 37-45, 1988.

[13] K. N. Ninan, "Kinetics of solid state thermal decomposition reactions," Journal of Thermal Analysis, vol. 35, no. 4, pp. 1267-1278, 1989.

[14] J. J. M. Orfao and F. G. Martins, "Kinetic analysis of solid state thermal decomposition reactions," Thermochimica Acta, vol. 390, pp. 195-201, 2002.

[15] I. Prigogine and R. Defay, Chemical Thermodynamics, Longmans Green and Co., London, UK, 1954.

[16] O. F. Shlensky and E. F. Vaynshteyn, "Thermal analysis study of the dynamic decomposition of polymers during rapid heating, limiting temperatures of thermolysis," Journal of Thermal Analysis and Calorimetry, vol. 35, no. 5, pp. 1477-1482, 1989.

[17] E. F. Vainstein and G. E. Zaikov, "Role of chain length in degradation process (chain breakdown)," Journal of Applied Polymer Science, vol. 84, no. 10, pp. 1810-1817, 2002.

[18] N. M. Emanuel and D. G. Knorre, Chemical Kinetics, Vysshaya Shkola, Moscow, russia, 1984.

[19] M. A. Semiokhin, S. A. Strakhov, and A. N. Osipov, Kinetics of Chemical Reactions, Moscow State University, 1995.

[20] J. Sestak, Thermochemical Properties of Solids, Academica, Prague, Czech Republic, 1984.

[21] V. Indira and G. Parameswaran, "Thermal decomposition kinetics of salicylideneaminofluorene complexes of Cobalt(II) and Nickel(II)," Thermochimica Acta, vol. 101, pp. 145-154, 1986.

[22] L. T. Vlaev, I. G. Markovska, and L. A. Lyubchev, "Non-isothermal kinetics of pyrolysis of rice husk," Thermochimica Acta, vol. 406, no. 1-2, pp. 1-7, 2003.

[23] L. H. McAmish and F. J. Johnston, "Sulfur exchange and decomposition kinetics in solid $\mathrm{Na}_{2} \mathrm{~S}_{2} \mathrm{O}_{3}$," Journal of Inorganic and Nuclear Chemistry, vol. 38, no. 3, pp. 537-540, 1976.

[24] G. W. Collet and B. Rand, "Thermogravimetric investigation of the pyrolysis of pitch materials. A compensation effect and variation in kinetic parameters with heating rate," Thermochimica Acta, vol. 41, pp. 153-165, 1980.

[25] R. K. Agrawal, “On the compensation effect," Journal of Thermal Analysis, vol. 31, no. 1, pp. 73-86, 1986.

[26] J. M. Criado, L. A. Perez-Maqueda, and P. E. sanchez-Jimenez, "Dependence of pre-exponential factor on temperature," Journal of Thermal Analysis and Calorimetry, vol. 82, pp. 671-678, 2005.

[27] L. Liu and Q. X. Guo, "Isokinetic relationship, isoequilibrium relationship, and enthalpy-entropy compensation," Chemical Reviews, vol. 101, no. 3, pp. 673-695, 2001.

[28] O. Exner, "On the enthalpy-entropy-relationship," Collection of Czechoslovak Chemical Communications, vol. 29, pp. 10941113, 1964.

[29] L. D. Peterson and S. D. Kevan, "Desorption and molecular interactions on surfaces: $\mathrm{CO} / \mathrm{Cu}(001)$ and $\mathrm{Cu}(011)$," The Journal of Chemical Physics, vol. 94, no. 3, pp. 2281-2293, 1991.

[30] R. R. Krug, W. G. Hunter, and R. A. Grieger, "Enthalpyentropy compensation. 2. Separation of the chemical from the statistical effect," Journal of Physical Chemistry, vol. 80, no. 21, pp. 2341-2351, 1976. 

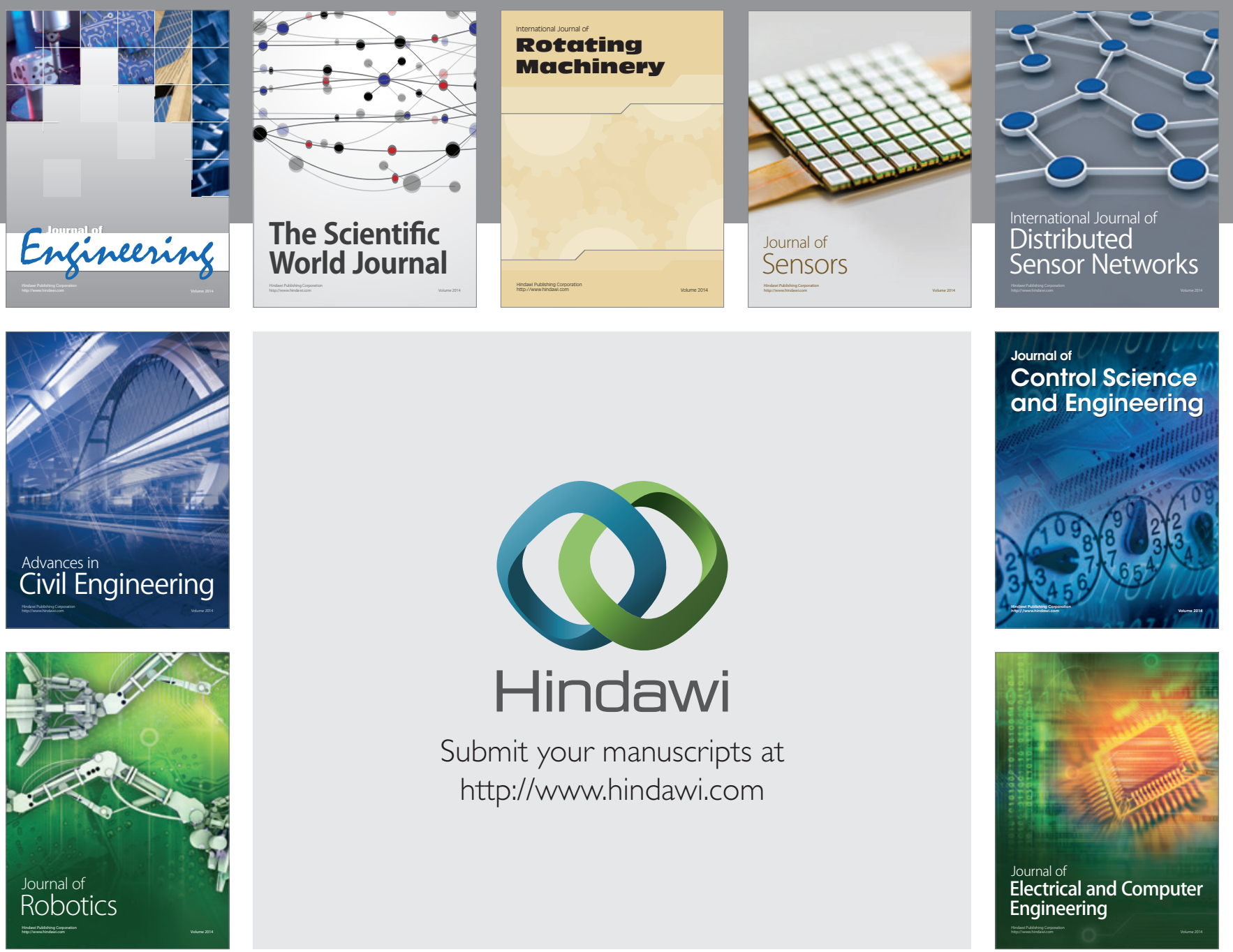

Submit your manuscripts at

http://www.hindawi.com
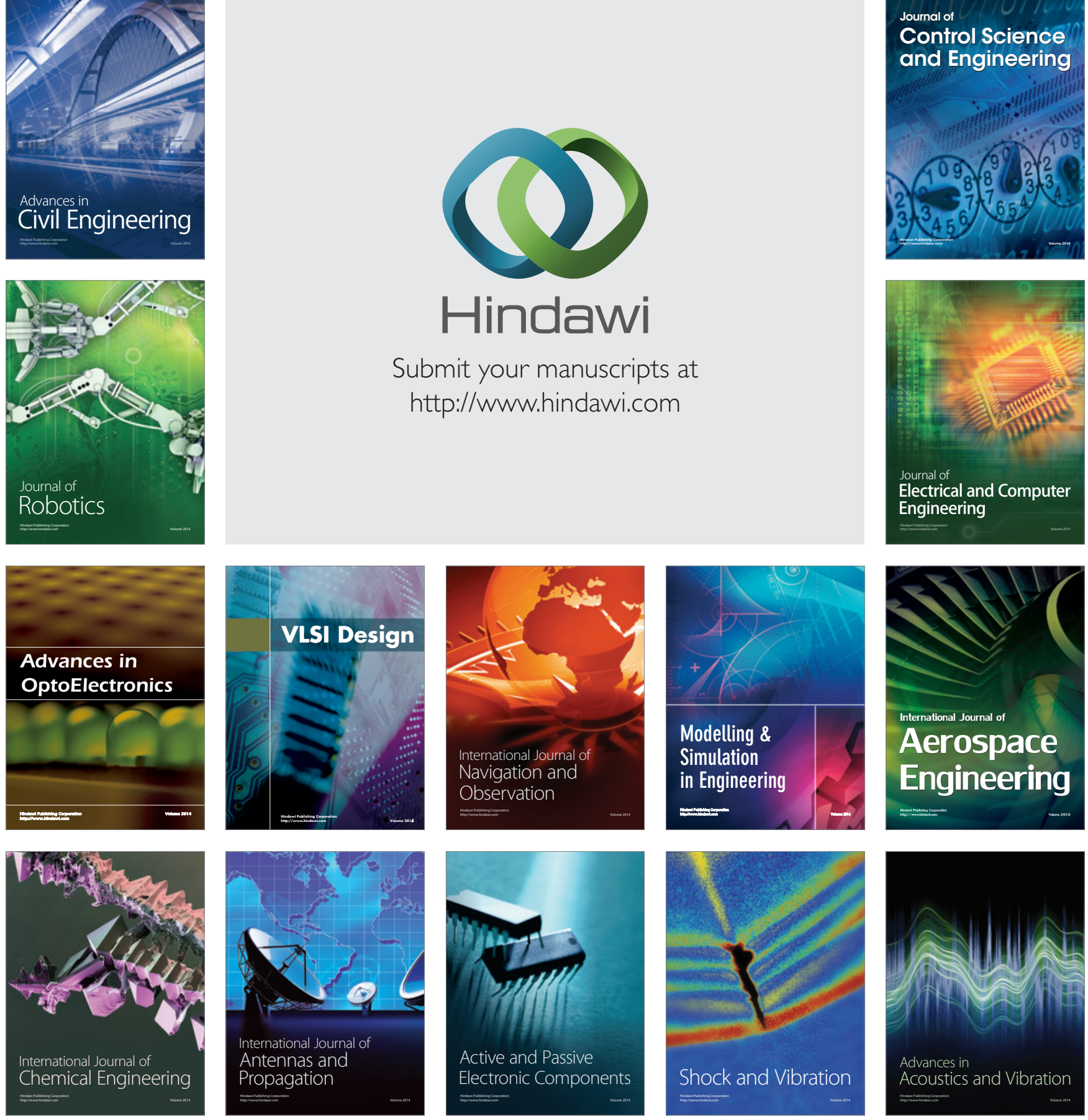